\title{
Cryopreserved valved femoral vein homografts for right ventricular outflow tract reconstruction in infants
}

\author{
Lok Sinha, MD, ${ }^{\mathrm{a}}$ Lucas Mota, BS, ${ }^{\mathrm{a}}$ Mahmut Ozturk, MD, ${ }^{\mathrm{b}}$ Steven J. Staffa, MS, \\ David Zurakowski, MS, PhD, ${ }^{\mathrm{c}}$ Richard A. Jonas, MD, ${ }^{\mathrm{a}}$ and Pranava Sinha, $\mathrm{MD}^{\mathrm{a}}$
}

\section{ABSTRACT}

Background: We have previously reported use of cryopreserved valve femoral vein homograft $(\mathrm{FVH})$ conduits for biventricular repairs in infants needing right ventricular outflow tract (RVOT) reconstruction. This study aims to compare FVH conduits with aortic $(A)$ and pulmonary $(P)$ homografts with regards to intermediate- and long-term outcomes.

Methods: Retrospective review was conducted of all infants between 2004 and 2016 who underwent biventricular repair with RVOT reconstruction using homograft conduits. Patients were divided into $\mathrm{A}, \mathrm{P}$, and $\mathrm{FVH}$ groups based upon type of conduit received $(\mathrm{N}=57[\mathrm{~A}=13 ; \mathrm{P}=21, \mathrm{FVH}=23])$. Groups were compared using univariate and multivariable Cox regression analyses. The Nelson-Aalen estimator of cumulative hazard and Kaplan-Meier curves were used to identify differences in freedom from catheter reintervention and reoperation.

Results: The 2 groups were comparable except for greater incidence of delayed sternal closure and longer hospital length of stay in the FVH group. The followup was longer for $\mathrm{A}$ and $\mathrm{P}$ groups compared with the $\mathrm{FVH}$ group $(P<.001)$. Multivariable Cox regression, adjusting for difference in the length of follow-up, revealed comparable freedom from overall reintervention between the groups. Younger age at implantation was the only independent predictor of overall reintervention (hazard ratio per day younger age, 1.06; 95\% confidence interval, 1.02-1.11; $P=.002$ ). Nelson-Aalen cumulative hazard analysis revealed greater freedom from percutaneous reintervention with use of FVH. Kaplan-Meier analysis showed comparable freedom from reoperation for all three conduits.

Conclusions: Valved femoral vein homograft conduits are comparable with aortic and pulmonary homografts for RVOT reconstruction in infants undergoing biventricular repairs. (JTCVS Open 2020;4:58-65)

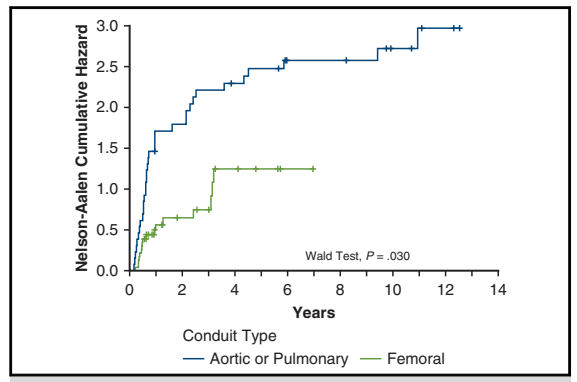

Comparison of femoral vein, aortic, and pulmonary homografts-time to event analyses.

\section{CENTRAL MESSAGE}

Valved femoral vein homograft

conduits are comparable with

pulmonary and aortic homo-

grafts for right ventricular

outflow tract reconstruction in

neonates or infants.

\section{PERSPECTIVE}

Early results of valved femoral vein homograft (FVH) conduits for biventricular cardiac surgical repairs in infants for reconstruction of right ventricular outflow tract show freedom from reoperation comparable to aortic and pulmonary homografts; and a lower need for percutaneous reintervention.

See Commentaries on pages 66 and 68.

$\square$ Video clip is available online.

From the a Department of Cardiovascular Surgery, Children's National Health Sys-

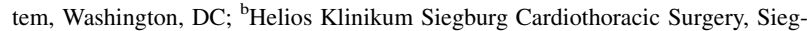
burg, Germany; and ${ }^{c}$ Departments of Anesthesiology and Surgery, Boston Children's Hospital Boston, Harvard Medical School, Boston, Mass.

Received for publication Aug 11, 2020; revisions received Aug 11, 2020; accepted for publication Aug 20, 2020; available ahead of print Oct 14, 2020.

Address for reprints: Pranava Sinha, MD, Department of Cardiovascular Surgery, Children's National Health System, 111 Michigan Ave NW, Washington, DC 20010 (E-mail: psinha@childrensnational.org).

2666-2736

Copyright $\odot 2020$ The Authors. Published by Elsevier Inc. on behalf of The American Association for Thoracic Surgery. This is an open access article under the CC BY-NCND license (http://creativecommons.org/licenses/by-nc-nd/4.0/).

https://doi.org/10.1016/j.xjon.2020.08.010
Anatomic continuity between the right ventricle and pulmonary arteries during reparative cardiac surgery in neonates and infants often requires placement of a valved conduit. Current surgical options for conduits for small patients with complex disease include aortic or pulmonary homografts and bovine jugular venous valved conduits (Contegra; Medtronic Inc, Minneapolis, Minn). ${ }^{1}$ Aortic and pulmonary homografts are in short supply, especially in the small size range required for the neonatal and infant patient population. 


\section{Abbreviations and Acronyms \\ $\mathrm{FVH}=$ femoral vein homograft \\ IQR = interquartile range \\ RVOT $=$ right ventricular outflow tract \\ $\mathrm{RV}-\mathrm{PA}=$ right ventricle to pulmonary artery}

Bovine jugular venous valved conduits are readily available on the shelf but may have an increased risk of early and late infective endocarditis. ${ }^{2-5}$ We have previously reported early results with the use of cryopreserved valved femoral vein homograft $(\mathrm{FVH})$ conduits for right ventricular outflow tract (RVOT) reconstruction in infants. ${ }^{6,7}$ The purpose of this study is to compare outcomes of FVH conduits with aortic and pulmonary homografts in the intermediate- and longer-term follow-up.

\section{METHODS}

A waiver of documented consent was granted by the Children's National Medical Center institutional review board due to the retrospective nature of the study. Data on all neonates and infants (age $<1$ year) who underwent 1stage biventricular repair needing a right ventricle to pulmonary artery (RV-PA) conduit between January 2004 and December 2016 were retrospectively reviewed. Depending upon the type of conduit used, the cohort was divided into the FVH, aortic homograft, or pulmonary homograft groups.

Patients with pulmonary atresia, ventricular septal defect, and major aortopulmonary collaterals who had conduits placed to promote growth of diminutive pulmonary arteries or unifocalized pulmonary vasculature were excluded from the study because need for reoperation and reintervention in this population is influenced by multiple nonconduit-related factors. Demographic, preoperative, intraoperative, postoperative, and follow-up data were recorded and compared between the 3 groups.

The primary end points were freedom from percutaneous reintervention on the conduit, conduit reoperations (surgical replacement/revision), or both (overall reintervention). Intraoperative and immediate postoperative variables constituted the secondary end points.

\section{Surgical Technique}

All patients underwent biventricular complete intracardiac repair and RVOT reconstruction via a median sternotomy with hypothermic cardiopulmonary bypass support. Deep hypothermic circulatory arrest was performed as indicated when aortic arch reconstruction was required. RVOT reconstruction was performed using a valved segment of $\mathrm{FVH}$ (FVH group) or aortic (A) or pulmonary (P) homograft conduit. The operative technique has been described in our previous report. ${ }^{7}$ Additional procedures were performed as indicated by the cardiac anatomy (Video 1).

The indication for catheter- or surgical-based reintervention was severe conduit stenosis, insufficiency, or a combination of moderate stenosis and moderate conduit insufficiency as determined either by echocardiogram, cardiac magnetic resonance imaging, or hemodynamic cardiac catheterization; was similar for all 3 groups; and was standard throughout the study duration. Criteria for reintervention/reoperation are summarized in Table 1 and remained standard for all conduits and throughout the study duration.

\section{Statistical Analysis}

Univariate analysis was performed to compare demographic, perioperative, and follow-up data between the 3 groups. Continuous data are

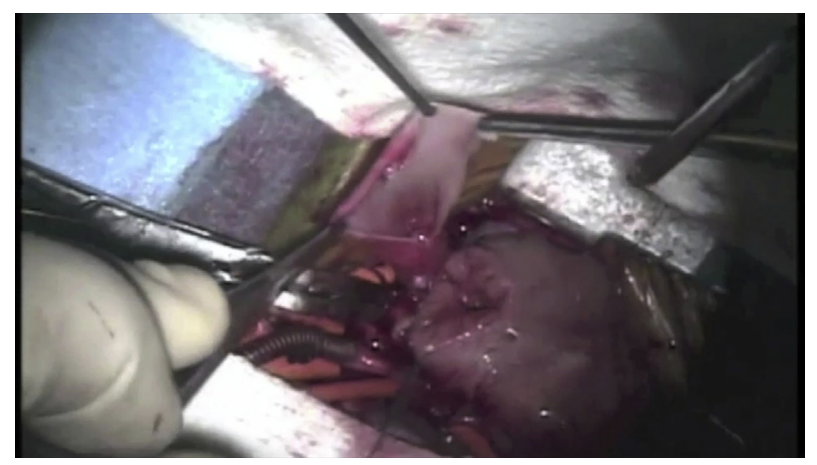

VIDEO 1. Truncus arteriosus repair in a 9-day-old child weighing $2.4 \mathrm{~kg}$ using femoral vein homograft for right ventricular outflow tract reconstruction. Video available at: https://www.jtcvs.org/article/S2666-2736(20) 30083-8/fulltext.

presented as median (interquartile range [IQR]) and were compared using the Mann-Whitney $U$ test. Proportions were compared using the Fisher exact test and categorical data by the $\chi^{2}$ test. Follow-up data were analyzed for freedom from catheter intervention in a modulated renewal approach using the Nelson-Aalen estimator of the cumulative hazard to compare reintervention since some patients had multiple events. ${ }^{8}$

Kaplan-Meier curves for reoperation were compared with the log-rank test, and $95 \%$ confidence limits for survival estimates were obtained using Greenwood's formula. Multivariate Cox regression was applied to compare freedom from catheter reintervention, freedom from reoperation, and freedom from either intervention, controlling for conduit diameter and length of follow-up as covariates. The results of Cox regression modeling are presented with hazard ratios, $95 \%$ confidence intervals, and $P$ values (Figures 1 and 2).

Data were analyzed using Stata 15.0 (Stata Corp, College Station, Tex) and R software (R Foundation for Statistical Computing, Vienna, Austria) A 2-tailed alpha level of 0.05 was used to determine statistical significance.

\section{RESULTS}

Between January 2004 and December 2016, a total cohort of 57 consecutive patients (aortic $=13$; pulmonary $=21$, $\mathrm{FVH}=23$ ) younger than 1 year underwent 1 -stage complete biventricular repair using an RV-PA conduit. Age at operation median (IQR) (aortic, 8 [7-14] days; pulmonary, 35 [7-105] days; and FVH, 17 [5-61] days [ $P=.17])$ and weight at operation, mean \pm standard deviation in kilograms (aortic, $3.35 \pm 0.7$; pulmonary, $3.44 \pm 1.4$; and FVH, $3.23 \pm 1.5$. $[P=.75])$ was similar between the groups. Demographic, anatomic, operative, postoperative, and followup data are detailed in Table 2.

We switched to using the FVH in 2008; therefore, all patients in the FVH group were operated on between 2008 and 2016, whereas the majority of patients in the A and P groups underwent surgery before 2008. The groups were comparable in terms of age, weight, cardiac diagnosis, and chromosomal anomalies. More female patients received the pulmonary homograft $(67 \%)$ compared with the aortic $(46 \%)$ and FVHs $(44 \%)(P=.03)$. A greater incidence of delayed sternal closure and longer hospital length of stay was noted in the FVH group (delayed sternal closure, 
TABLE 1. Institutional criteria for percutaneous reintervention and reoperation

\begin{tabular}{|c|c|c|}
\hline & Percutaneous reintervention & Surgical reoperation \\
\hline Conduit stenosis & $\begin{array}{l}\text { Severe RVOT obstruction } \\
\text { - Peak to peak gradient across RVOT of }>40 \mathrm{~mm} \mathrm{Hg} \text { by } \\
\text { cardiac catheterization } \\
\text { - Peak velocity across RVOT of }>4 \mathrm{~m} / \mathrm{s} \text { by Doppler } \\
\text { echocardiograms } \\
\text { - RV systolic pressure } \geq 2 / 3 \text { systemic pressure by } \\
\text { echocardiograms or cardiac catheterization } \\
\text { - Clinically significant RVOT obstruction in the presence of } \\
\text { RV dysfunction }\end{array}$ & $\begin{array}{l}\text { Same as percutaneous reintervention } \\
+ \\
\text { not amenable to percutaneous reintervention }\end{array}$ \\
\hline $\begin{array}{l}\text { Conduit } \\
\text { regurgitation }\end{array}$ & $\begin{array}{l}\text { (lack of suitable percutaneous PPV options for small } \\
\text { conduits) }\end{array}$ & $\begin{array}{l}\text { - Moderate or greater } \mathrm{RV} \text { dysfunction in the presence of } \\
\text { moderate or greater conduit regurgitation } \\
\text { - Severe or progressive } \mathrm{RV} \text { dilatation (RV end-diastolic } \\
\text { volume index } \geq 160 \mathrm{~mL} / \mathrm{m}^{2} \text {, estimated by serial } \mathrm{cMRI} \text { ) }\end{array}$ \\
\hline Symptoms/signs & $\begin{array}{l}\text { - Symptomatic RVOT obstruction or regurgitation } \\
\text { - Progressive reduction in exercise capacity }\end{array}$ & \\
\hline
\end{tabular}

Reinterventions indicated in presence of symptoms or signs, severe conduit stenosis or regurgitation, or both. Surgical reoperation indicated for all percutaneous reinterventions not amenable to percutaneous therapies. $R V O T$, Right ventricle outflow tract; $R V$, right ventricle; $P P V$, percutaneous pulmonary valve; $c M R I$, cardiac magnetic resonance imaging.

numbers [\%]; A, 4 [30]; P, 2 [9]; FVH, 12 [52] [P=.009]; hospital LOS, days, median [IQR]; A, 21 [14-66]; P, 17 [1127]; FVH, 32 [25-52] $[P=.01])$. There were no operative mortalities in the series. The follow-up was longer for A and $\mathrm{P}$ groups compared with the FVH group (median
[IQR] years; A, 9.6 [5.8-10.9]; P, 8 [5.4-11.9]; FVH, 1.8 $[0.9-3.2][P<.001])$. The majority of index conduits of FVH were still in situ $(69 \%)$, as compared with the A/P group $(32 \%)(P=.001)$. There were no cases of conduit endocarditis.

\section{FEMORAL VEIN HOMOGRAFTS FOR RIGHT VENTRICULAR OUTFLOW TRACT RECONSTRUCTION IN INFANTS}

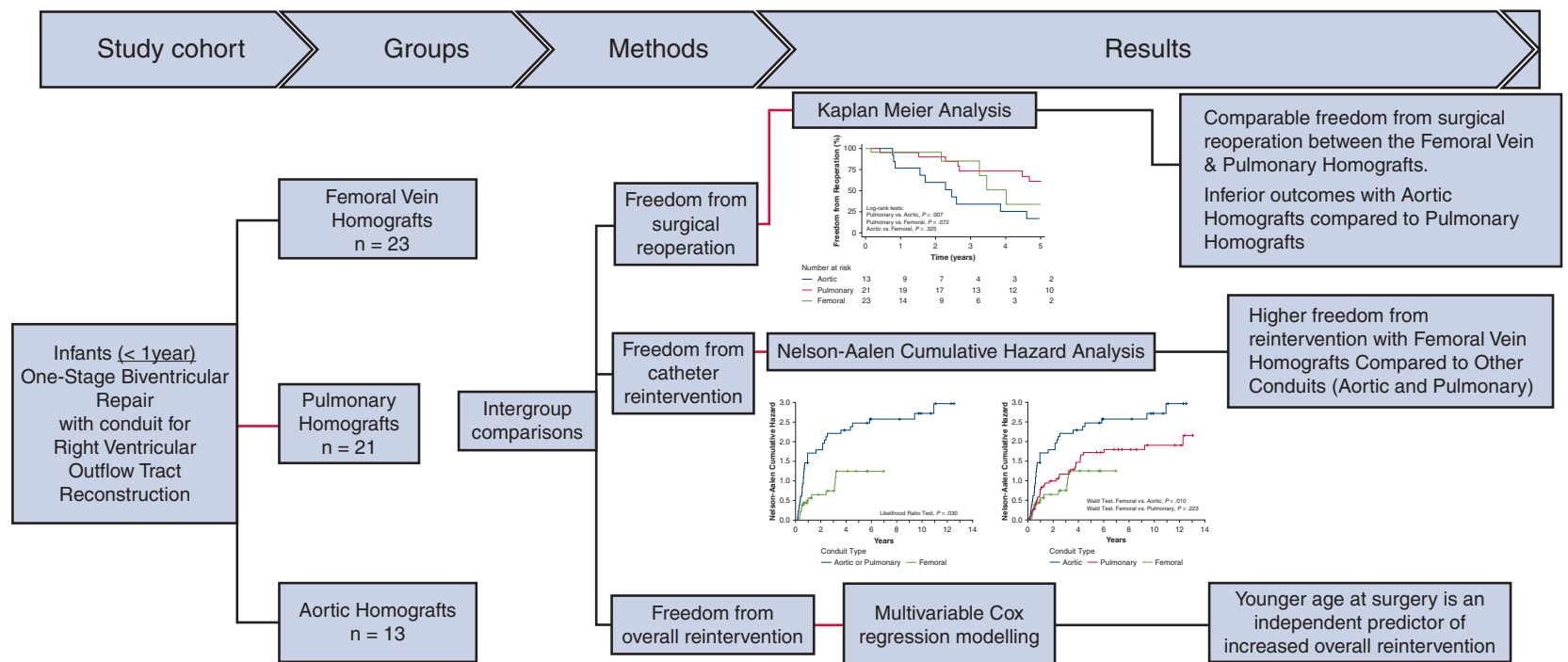

Implications: Valved femoral vein homograft conduits have comparable freedom from reoperation to aortic and pulmonary homografts when used for right ventricular outflow tract reconstruction in infants undergoing biventricular repairs. Freedom from percutaneous reintervention may be lower with use of femoral vein homografts. Additional long-term studies are needed to evaluate the long-term outcomes of femoral vein homograft conduits

FIGURE 1. Study cohort, groups, methods, and results. The 3 groups of patients (femoral vein homograft, pulmonary homograft, and aortic homograft) were compared for freedom from surgical reoperation using Kaplan-Meier analysis, freedom from percutaneous reintervention using Nelson-Aalen cumulative hazard analysis and multivariable Cox regression analysis for overall freedom from reintervention. The study revealed comparable freedom from surgical reoperation and a greater freedom from percutaneous reintervention for femoral vein homografts compared with other conduits. Younger age at conduit placement was an independent predictor of lower freedom from overall reintervention. 

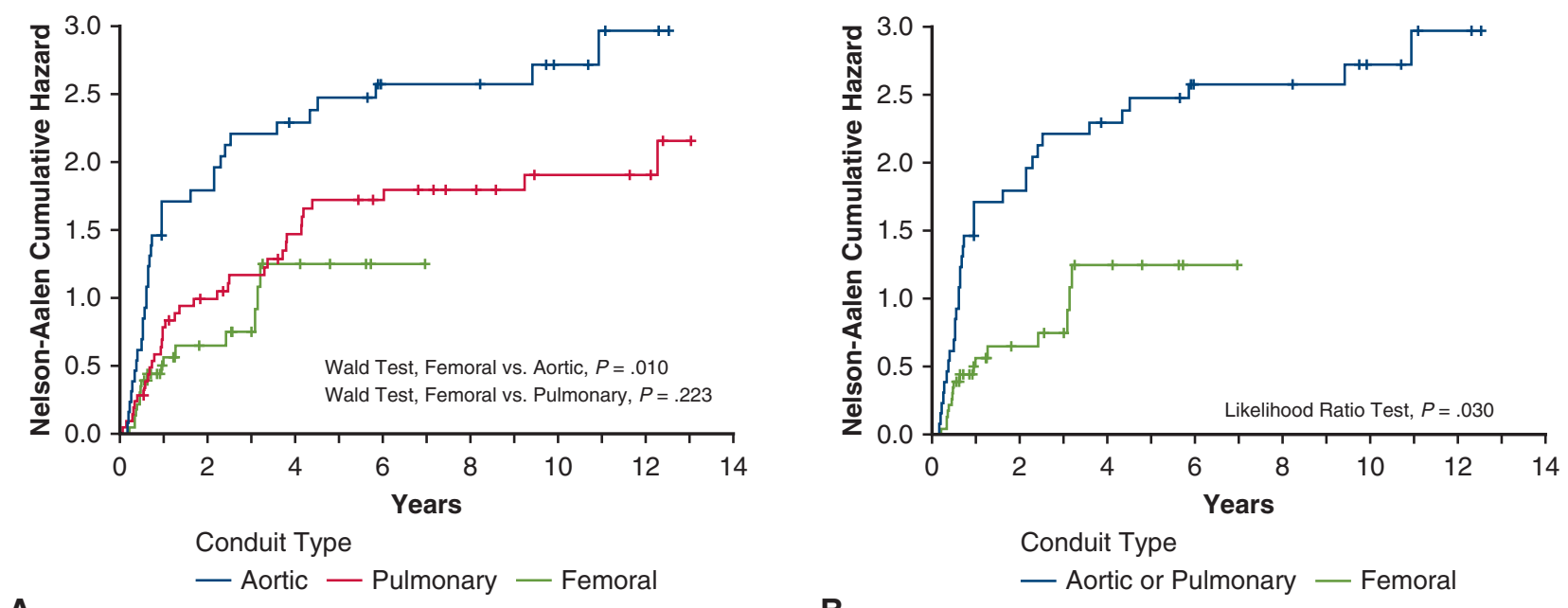

A

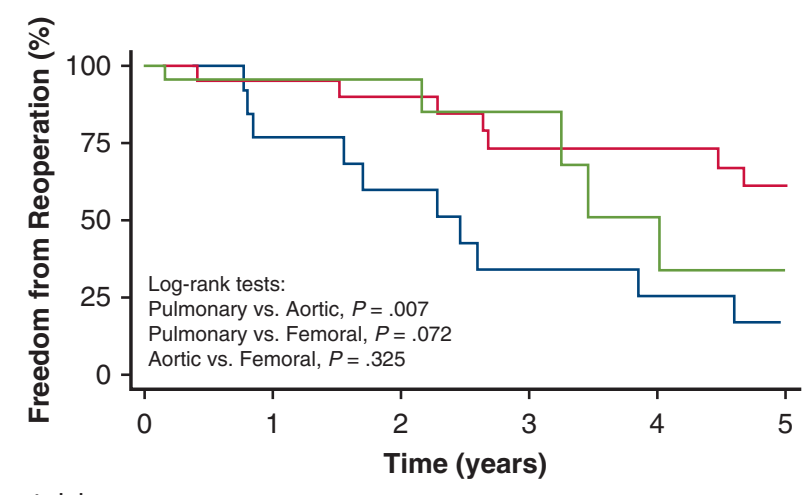

$\begin{array}{llr}\text { Number at risk } & & \\ \text { - Aortic } & 13 & 9 \\ \text { - Pulmonary } & 21 & 19 \\ \text { - Femoral } & 23 & 14 \\ \text { C } & & \end{array}$

$\begin{array}{rrrr}7 & 4 & 3 & 2 \\ 17 & 13 & 12 & 10 \\ 9 & 6 & 3 & 2\end{array}$

FIGURE 2. Comparison of femoral vein homografts with aortic and pulmonary homografts using time-event analysis. A, Nelson-Aalen cumulative hazard for freedom from percutaneous reintervention between femoral vein, aortic, and pulmonary homografts. The $Y$-axis shows the cumulative hazard for percutaneous intervention against time on the $X$-axis. Aortic (blue line), pulmonary (red line), and femoral vein (green line) homografts are depicted separately. The Wald test revealed a lower cumulative reintervention hazard for femoral vein homografts compared with aortic homografts $(P=.010)$. The graph also shows a trend toward lower cumulative reintervention hazard for femoral vein homografts compared with pulmonary homografts, although not statistically significant $(P=.223)$. B, Nelson-Aalen cumulative hazard for freedom from catheter reintervention comparing femoral vein ( $g$ reen line $)$ with other conduits (aortic and pulmonary) (blue line). The $Y$-axis shows the cumulative hazard for percutaneous intervention against time on the $X$-axis. The Wald test revealed a lower cumulative reintervention hazard for femoral vein homografts compared with other homografts $(P=.030)$. C, Kaplan-Meier analysis for freedom from reoperation by conduit type. Aortic (blue line), pulmonary (red line), and femoral vein (green line) conduits are depicted separately. Pulmonary conduits demonstrate superior freedom from reoperation as compared with aortic conduits (log-rank test, $P=.007$ ). There were no statistically significant differences between pulmonary and femoral conduits (log-rank test, $P=.072$ ) or between aortic and femoral conduits $(\log$-rank test, $P=.325)$. Kaplan-Meier estimates for freedom from reoperation with confidence limits are summarized in Table 6.

Multivariable Cox regression adjusting for the intergroup differences in the length of follow-up revealed comparable freedom from catheter reintervention, freedom from reoperation, and freedom from either intervention in the FVH and the A/P groups. Younger age at implantation was the only independent predictor for increased overall reintervention (hazard ratio, 1.06; 95\% confidence interval, 1.02-1.11; $P=.002)$. Results of multivariable analysis of risk factors for reintervention are detailed in Table 3.
Over the study period, 30 conduits required replacement (aortic, 11; pulmonary, 12; and FVH, 7). The status of 27 remaining index conduits in situ at the time of study completion is detailed in Table 4. Comparable rates of conduit stenosis were seen between pulmonary and femoral vein conduits, but a greater incidence of conduit insufficiency was noted in the femoral vein group compared with the pulmonary homografts. 
TABLE 2. Demographic, anatomical, operative, postoperative, and follow-up data comparing femoral vein homografts with aortic and pulmonary homografts

\begin{tabular}{|c|c|c|c|c|}
\hline Variable & $\operatorname{Aortic}(n=13)$ & Pulmonary $(n=21)$ & Femoral $(\mathbf{n}=23)$ & $P$ value \\
\hline \multicolumn{5}{|l|}{ Demographic and anatomical data } \\
\hline Female sex, n $(\%)$ & $6(46)$ & $14(67)$ & $20(44)$ & $.03 *$ \\
\hline Known syndrome, n (\%) & $1(7)$ & $3(14)$ & $1(4)$ & .6 \\
\hline Chromosomal abnormality, n (\%) & 0 & $1(4)$ & $1(4)$ & 1.0 \\
\hline \multicolumn{5}{|l|}{ Anatomical diagnosis, $\mathrm{n}(\%)$} \\
\hline Truncus arteriosus & $7(53)$ & $4(19)$ & $7(30)$ & .09 \\
\hline TOF with pulmonary atresia & $5(38)$ & $8(38)$ & $8(34)$ & .96 \\
\hline DORV including Taussig-Bing anomaly & & $6(28)$ & $4(17)$ & \\
\hline Aortic atresia with IAA and VSD & & $1(4)$ & & \\
\hline TGA with VSD & $1(7)$ & $1(4)$ & $1(4)$ & \\
\hline Coronary Anomaly & & $1(4)$ & & \\
\hline Hemi-truncus & & & $1(4)$ & \\
\hline ALCAPA & & & $1(4)$ & \\
\hline L-TGA & & & $1(4)$ & \\
\hline \multicolumn{5}{|l|}{ Operative data } \\
\hline Age at operation, d, median (IQR) & $8(7-14)$ & $35(7-105)$ & $17(5-61)$ & .17 \\
\hline Weight at operation, $\mathrm{kg}$, mean $\pm \mathrm{SD}$ & $3.35 \pm 0.7$ & $3.44 \pm 1.4$ & $3.23 \pm 1.5$ & .75 \\
\hline Size of conduit, mm, median (IQR) & $9(9-11)$ & $11(9-13)$ & $11(10-13)$ & .08 \\
\hline $\mathrm{CPB}$ time, min, mean $\pm \mathrm{SD}$ & $134 \pm 25$ & $139 \pm 56$ & $146 \pm 43$ & .76 \\
\hline Crossclamp time, min, mean \pm SD & $83 \pm 17$ & $71 \pm 19$ & $80 \pm 24$ & .20 \\
\hline DHCA, n $(\%)$ & $7(53)$ & $7(33)$ & $9(39)$ & .48 \\
\hline DHCA time, min, mean \pm SD & $12 \pm 13$ & $7 \pm 15$ & $4 \pm 10$ & .23 \\
\hline \multicolumn{5}{|l|}{ Type of operative procedure } \\
\hline Truncus arteriosus repair & $7(53)$ & $4(19)$ & $7(30)$ & \\
\hline IAA repair & & $1(4)$ & & \\
\hline Rastelli procedure & $3(23)$ & $7(33)$ & $3(14)$ & \\
\hline Conduit placement, $\mathrm{RV}$ to $\mathrm{PA}$ & $3(23)$ & $2(9)$ & $8(34)$ & \\
\hline Stage-1 repair of TOF with PA & & $5(23)$ & $1(4)$ & \\
\hline ALCAPA repair & & $1(4)$ & $1(4)$ & \\
\hline ASO with VSD repair & & $1(4)$ & $1(4)$ & \\
\hline Hemi-truncus & & & $1(4)$ & \\
\hline L-TGA & & & $1(4)$ & \\
\hline Delayed sternal closure, $\mathrm{n}(\%)$ & $4(30)$ & $2(9)$ & $12(52)$ & $.009 *$ \\
\hline STAT category & $4(3-4)$ & $4(3-4)$ & $3(2-4)$ & .61 \\
\hline \multicolumn{5}{|l|}{ Postoperative data } \\
\hline Ventilation time, d, median (IQR) & $6(3-9)$ & $5(3-7)$ & $7(5-9)$ & .09 \\
\hline ICU LOS, d, median (IQR) & $10(8-20)$ & $9(7-14)$ & $15(9-21)$ & .16 \\
\hline Hospital LOS, d, median (IQR) & $21(14-66)$ & $17(11-27)$ & $32(25-52)$ & $.01 *$ \\
\hline Need for ECMO support, n (\%) & 0 & 0 & $1(4)$ & 1.0 \\
\hline Operative mortality, n (\%) & 0 & 0 & 0 & 1.0 \\
\hline \multicolumn{5}{|l|}{ Follow-up data } \\
\hline Follow-up, y, median (IQR) & $9.6(5.8-10.9)$ & $8(5.4-11.9)$ & $1.8(0.9-3.2)$ & $<.001 *$ \\
\hline Conduit reoperations, n (\%) & $11(84)$ & $12(57)$ & $7(30)$ & .004 \\
\hline Time from original conduit to replacement, y, median (IQR) & $2.2(1.9-2.3)$ & $4.5(2.3-6.7)$ & $3.41(2.1-5.3)$ & .15 \\
\hline Index conduit still in situ, $\mathrm{n}(\%)$ & $2(15)$ & $9(42)$ & $16(69)$ & $<.001 *$ \\
\hline
\end{tabular}

Categorical data presented as numbers (proportions). Continuous data are presented as mean $\pm \mathrm{SD}$ or median (IQR). Intergroup comparisons were done using the Fisher exact test, analysis of variance, and the Kruskal-Wallis test. TOF, Tetralogy of Fallot; $D O R V$, double-outlet right ventricle; $I A A$, interrupted aortic arch; VSD, ventricular septal defect; TGA, transposition of great arteries; $A L C A P A$, anomalous left coronary artery from pulmonary artery; $L$-TGA, levo-transposition of the great arteries; IQR, interquartile range; $S D$, standard deviation; $C P B$, cardiopulmonary bypass; $D H C A$, deep hypothermic circulatory arrest; $R V$, right ventricle; $P A$, pulmonary atresia; $A S O$, arterial switch operation; $S T A T$, Society of Thoracic Surgeons-European Association for Cardio-Thoracic Surgery score; ICU, intensive care unit; $L O S$, length of stay; ECMO, extracorporeal membrane oxygenation. *Statistically significant differences between groups.

The number of patients/number of percutaneous reinterventions between aortic, pulmonary, and $\mathrm{FVH}$ is summarized in Table 5. Nelson-Aalen cumulative hazard analysis revealed a greater rate of freedom from reintervention with use of FVH (Figure 2, $A$ and $B$ ). KaplanMeier analysis for freedom from reoperation by conduit 
TABLE 3. Multivariable analysis of risk factors for overall reintervention (catheter reintervention or surgical reoperation), controlling for conduit diameter and length of follow-up

\begin{tabular}{|c|c|c|}
\hline & $\begin{array}{l}\text { Hazard ratio }(95 \% \\
\text { confidence interval) }\end{array}$ & $P$ value \\
\hline \multicolumn{3}{|c|}{ Comparison of femoral vein, aortic, and pulmonary homografts } \\
\hline \multicolumn{3}{|l|}{ Conduit type } \\
\hline Femoral & Reference (-) & - \\
\hline Aortic & $1.88(0.78-4.49)$ & .157 \\
\hline Pulmonary & $1.64(0.67-3.99)$ & .276 \\
\hline Age at implantation, $\mathrm{d}$ & $1.06(1.02-1.11)$ & $.002 *$ \\
\hline Year of surgery & $0.99(0.87-1.12)$ & .829 \\
\hline Size of conduit, $\mathrm{mm} / \mathrm{kg}$ & $0.84(0.68-1.05)$ & .127 \\
\hline \multicolumn{3}{|c|}{$\begin{array}{l}\text { Comparison of femoral vein homografts with other conduits (aortic and } \\
\text { pulmonary homografts) }\end{array}$} \\
\hline \multicolumn{3}{|l|}{ Conduit type } \\
\hline Femoral & Reference (-) & - \\
\hline Aortic or pulmonary & $1.76(0.74-4.16)$ & .202 \\
\hline Age, d & $0.93(0.89-0.97)$ & $<.001 *$ \\
\hline Year of surgery & $0.99(0.87-1.12)$ & .850 \\
\hline Size of conduit, $\mathrm{mm} / \mathrm{kg}$ & $0.83(0.66-1.04)$ & .110 \\
\hline
\end{tabular}

Hazard ratios and $95 \%$ confidence intervals obtained from Cox proportional hazards regression modeling are presented for 10-unit increases for age and duration of follow-up. Models are adjusted for duration of follow-up (days). *Younger age at the time of implantation of conduit independently associated with increased reintervention.

type (aortic, femoral, and pulmonary) (Figure 2, C) revealed that pulmonary conduits demonstrated superior freedom from reoperation as compared with aortic conduits (log-rank test, $P=.007)$. There was no statistically significant difference between pulmonary and femoral conduits (log-rank test, $P=.072$ ) and between aortic and femoral conduits (log-rank test, $P=.325$ ). The confidence limits for freedom from reoperation at 6 months, 1 year, 3 years, and 5 years within each group are shown separately in Table 6 .

Summary of the findings are also summarized in Figure 1.

TABLE 4. Status of index conduits still in situ

\begin{tabular}{|c|c|c|c|c|}
\hline Variable & $\begin{array}{l}\text { Aortic } \\
(n=2)\end{array}$ & $\begin{array}{c}\text { Pulmonary } \\
(\mathbf{n}=9)\end{array}$ & $\begin{array}{l}\text { Femoral } \\
(n=16)\end{array}$ & $\begin{array}{c}P \\
\text { value }\end{array}$ \\
\hline Conduit stenosis, mild & & $1(11)$ & $4(25)$ & .75 \\
\hline Conduit stenosis, moderate & & $3(33)$ & $4(25)$ & 1.0 \\
\hline Conduit stenosis, severe & & & $7(44)$ & \\
\hline $\begin{array}{l}\text { Conduit stenosis and } \\
\text { insufficiency, mild }\end{array}$ & $1(50)$ & & & \\
\hline Conduit insufficiency, none & $1(50)$ & $6(66)$ & $3(19)$ & $.02 *$ \\
\hline Conduit insufficiency, mild & & $2(22)$ & $3(19)$ & \\
\hline $\begin{array}{l}\text { Conduit insufficiency, } \\
\text { moderate }\end{array}$ & & $1(11)$ & $7(44)$ & \\
\hline Conduit insufficiency, severe & & & $3(19)$ & \\
\hline
\end{tabular}

*Statistically significant differences between groups.
TABLE 5. Number of patients by number of percutaneous reinterventions between femoral vein homografts, aortic, and pulmonary homografts

\begin{tabular}{lccc}
\hline \multirow{2}{*}{$\begin{array}{c}\text { Number of } \\
\text { reinterventions }\end{array}$} & $\begin{array}{c}\text { Aortic } \\
(\mathbf{n}=\mathbf{1 3})\end{array}$ & $\begin{array}{c}\text { Pulmonary } \\
(\mathbf{n}=\mathbf{2 1})\end{array}$ & $\begin{array}{c}\text { Femoral } \\
(\mathbf{n}=\mathbf{2 3})\end{array}$ \\
\hline No. reinterventions & 0 & 6 & 12 \\
\hline 1 reintervention & 1 & 2 & 7 \\
\hline 2 reinterventions & 5 & 8 & 2 \\
\hline 3 reinterventions & 5 & 3 & 2 \\
\hline 4 reinterventions & 2 & 2 & 0 \\
\hline
\end{tabular}

Due to multiple percutaneous reinterventions, a modulated renewal analysis using the Nelson-Aalen cumulative hazard model was undertaken to analyze freedom from percutaneous reintervention (Figure 2, $A$ and $B$ ).

\section{COMMENT}

All available conduits for neonatal and infant cardiac surgical repairs have their advantages and disadvantages. ${ }^{1}$ Aortic and pulmonary homografts are in short supply in the sizes required for reconstruction in infants and neonates. After initial promise, ${ }^{1}$ bovine jugular vein grafts (Contegra) have been reported to have a disturbingly high incidence of early and late endocarditis. ${ }^{2-5}$ Pulmonary homografts are preferred for RVOT reconstruction due to lower calcification rate and conduit failure rate compared with aortic homografts ${ }^{1,9}$ and while size of the conduit is directly related to the durability of the conduit, ${ }^{1,10}$ there are limitations to oversizing of the conduit, given the size limitations in neonates and infants.

FVHs have the advantage of being widely available from adult cadaver donors in contrast to small size aortic and pulmonary homografts, which are usually supplied by rare pediatric donors. Adult FVH is available in 25-

TABLE 6. Kaplan-Meier estimates for freedom from reoperation with confidence limits

\begin{tabular}{lcc}
\hline Type of conduit & $\begin{array}{c}\text { Freedom from } \\
\text { reoperation }\end{array}$ & $\mathbf{9 5 \%}$ confidence limits \\
\hline Aortic & & \\
6 mo & $100 \%$ & - \\
1 y & $77 \%$ & $(44 \%, 92 \%)$ \\
3 y & $34 \%$ & $(11 \%, 60 \%)$ \\
5 y & $17 \%$ & $(3 \%, 42 \%)$ \\
Pulmonary & & \\
6 mo & $95 \%$ & $(71 \%, 99 \%)$ \\
1 y & $95 \%$ & $(71 \%, 99 \%)$ \\
3 y & $73 \%$ & $(47 \%, 88 \%)$ \\
5 y & $61 \%$ & $(35 \%, 79 \%)$ \\
Femoral & & \\
6 mo & $96 \%$ & $(73 \%, 99 \%)$ \\
1 y & $96 \%$ & $(73 \%, 99 \%)$ \\
3 y & $85 \%$ & $(48 \%, 97 \%)$ \\
5 y & $34 \%$ & $(5 \%, 68 \%)$ \\
\hline
\end{tabular}


to $30-\mathrm{cm}$ length segments, with the diameter tapering from approximately $15 \mathrm{~mm}$ to $10 \mathrm{~mm}$ (ideal size range required for neonates or infants), and thus fill the size ranges particularly where the shortage of aortic and pulmonary homografts is most marked. Each FVH segment has an average of 2 to 4 competent valves, giving the surgeon the intraoperative ability to choose an appropriatesized valved segment. The material is thin-walled and ideally suited for anastomosis to the delicate, thinwalled distal pulmonary artery bifurcation in infants and neonates. Despite being thin-walled, it is hemostatic and can be directly anastomosed to the right ventricular incision without a hood, simplifying the technical aspects of the operation. The FVH is also considerably cheaper compared with the other alternatives, and with appropriate isolation and packaging of the vein segments (eg, isolating individual valved segments by vendors), has the potential for further cost savings.

A greater proportion of patients in the FVH group underwent delayed sternal closure in our series which can be attributed to a more liberal adoption of delayed sternal closure by our institution in the recent years. This also explains the longer hospital length of stay in this cohort. This approach, however, has led to no mortalities seen in this complex high-risk patient cohort. While these strategies which increase cost are offset by the lower need for catheter reintervention in the FVH group a detailed resource use analysis study will need to be performed to assess the true cost impact of different conduits.

We have extensively used the versatile FVH conduit for multiple corrective and palliative indications in congenital cardiac surgery. ${ }^{6,7,11-13}$ We previously reported our initial experience with valved $\mathrm{FVH}$ conduits for biventricular repairs requiring RVOT reconstruction in infants. ${ }^{6,7}$ This study presents our intermediate and long-term outcome of the FVH for early primary repair requiring RV-PA for RVOT reconstruction.

Our study demonstrates that pulmonary homografts continue to have superior outcomes compared with aortic homografts and should be the standard for comparing future conduits. FVH conduits offer a lower need for percutaneous reinterventions compared with the aortic and pulmonary homografts. The freedom from surgical reoperation (conduit change) was comparable between the FVH and pulmonary homografts. The pulmonary homografts were superior to the aortic homografts, as shown in previous studies. ${ }^{1,9}$ Younger age at surgery was an independent predictor of lower freedom from reintervention.

With regards to index conduits still in situ comparable rates of conduit stenosis were noted between pulmonary and femoral vein conduits but greater rates of conduit insufficiency were seen in the femoral vein group, which will require careful close evaluation in the longer term.
The biggest limitation of aortic or pulmonary homografts is their short supply in the sizes required for use in neonates and infants, whereas FVHs are most commonly available in those sizes. Bovine jugular vein conduits, while available off the shelf, have concerns for both early and late endocarditis as high as $10 \% \cdot{ }^{2-5}$ In our extensive experience with the use of FVHs over a wide variety of indications. ${ }^{6,7,11-13}$ there has not been a single case of endocarditis associated with its use.

This study has the limitations of being a single-center, retrospective study with a small number of patients. There is disparity in the duration of follow-up between the FVH and the $\mathrm{A}$ and $\mathrm{P}$ homograft groups. While there were no practice changes in the surgical technique other than the choice of conduit, or in the indications for reintervention/reoperation during the study duration, the confounding effect of the era of the surgery was minimized by addition of year of surgery as a variable into our multivariable model as well as the modulated renewal Nelson-Aalen cumulative hazard model. Aortic homografts were used more often in patients with truncus arteriosus and overall were smaller compared with pulmonary and femoral homografts. While these differences were not statistically significant, they could account for inferior outcomes seen with aortic homografts seen in this series. With a proportion of patients with index conduits in situ, the development of conduit disease over a longer-term follow-up needs to be assessed.

Our data clearly show that the FVH conduits are comparable with aortic and pulmonary homografts for RVOT reconstruction in neonates and infants undergoing 1-stage biventricular repair. The need for percutaneous reinterventions was also lower for FVH compared with aortic or pulmonary homografts. Using the Nelson-Aalen estimator of the cumulative hazard to compare percutaneous reintervention, 1.25 reinterventions were needed for any patient with FVH over the first 4 years. In a similar time frame, if the patient had an aortic/pulmonary homograft conduit, 2.25 reinterventions were required.

Current market value for FVH is $\$ 6000.00$, whereas pulmonary and aortic homograft cost $\$ 13,000.00$. Most FVH segments have 2 to 3 competent valves and with industry collaboration there is a potential to isolate individual valved segments and further reduce the cost of FVH 2to 3-fold.

\section{CONCLUSIONS}

While pulmonary homografts continue to be superior to aortic homografts, valved FVH conduits may be a suitable alternative, with comparable freedom from reoperation to aortic and pulmonary homografts when used for RVOT reconstruction in infants undergoing biventricular repairs. Freedom from percutaneous reintervention may be lower with the use of FVH. Careful longer-term evaluation of FVH conduits is needed, especially to assess conduit valve 
function. Low cost, ready availability, and comparable outcomes make FVHs an attractive alternative to aortic and pulmonary homografts.

\section{Conflict of Interest Statement}

The authors reported no conflicts of interest.

The Journal policy requires editors and reviewers to disclose conflicts of interest and to decline handling or reviewing manuscripts for which they may have a conflict of interest. The editors and reviewers of this article have no conflicts of interest.

\section{References}

1. Poynter JA, Eghtesady P, McCrindle BW, Walters HL III, Kirshbom PM, Blackstone EH, et al. Association of pulmonary conduit type and size with durability in infants and young children. Ann Thorac Surg. 2013;96:1695-701; discussion 1701-2.

2. Beckerman Z, De Leon LE, Zea-Vera R, Mery CM, Fraser CD Jr. High incidence of late infective endocarditis in bovine jugular vein valved conduits. $J$ Thorac Cardiovasc Surg. 2018;156:728-34.e2.

3. Patel PM, Tan C, Srivastava N, Herrmann JL, Rodefeld MD, Turrentine MW, et al. Bovine jugular vein conduit: a mid- to long-term institutional review. World J Pediatr Congenit Heart Surg. 2018:9:489-95.

4. Ugaki S, Rutledge J, Al Aklabi M, Ross DB, Adatia I, Rebeyka IM. An increased incidence of conduit endocarditis in patients receiving bovine jugular vein grafts compared to cryopreserved homograft for right ventricular outflow reconstruction. Ann Thorac Surg. 2015;99:140-6.
5. Mery CM, Guzman-Pruneda FA, De Leon LE, Zhang W, Terwelp MD Bocchini CE, et al. Risk factors for development of endocarditis and reintervention in patients undergoing right ventricle to pulmonary artery valved conduit placement. J Thorac Cardiovasc Surg. 2016;151:432-9. 441.e1-2.

6. Schiller O, Sinha P, Zurakowski D, Jonas RA. Reconstruction of right ventricular outflow tract in neonates and infants using valved cryopreserved femoral vein homografts. J Thorac Cardiovasc Surg. 2014;147:874-9.

7. Sinha P, Talwar S, Moulick A, Jonas R. Right ventricular outflow tract reconstruction using a valved femoral vein homograft. J Thorac Cardiovasc Surg. 2010;139:226-8.

8. Blackstone EH, Karamlou TB. What industry taught us about repeated timerelated events. J Thorac Cardiovasc Surg. 2018;155:737-8.

9. Eguchi S, Asano K. Homograft of pulmonary artery or ascending aorta with valve as a right ventricular outflow. J Thorac Cardiovasc Surg. 1968;56:413-20.

10. Tweddell JS, Pelech AN, Frommelt PC, Mussatto KA, Wyman JD, Fedderly RT, et al. Factors affecting longevity of homograft valves used in right ventricular outflow tract reconstruction for congenital heart disease. Circulation. 2000; 102:III130-5.

11. He D, Sinha P, Peer M, Jonas RA. Use of femoral vein homograft for unifocalizing major aortopulmonary collateral arteries in a patient with pulmonary atresia with ventricular septal defect. J Thorac Cardiovasc Surg. 2014;147:824-5.

12. Seery TJ, Sinha P, Zurakowski D, Jonas RA. Femoral vein homograft for neoaortic reconstruction in the norwood stage 1 operation: a follow-up study J Thorac Cardiovasc Surg. 2013;146:550-6.

13. Sinha P, Moulick A, Jonas RA. Femoral vein homograft for neoaortic reconstruction in norwood stage 1 operation. Ann Thorac Surg. 2009;87:1309-10.

Key Words: pulmonary valve, homograft, CHD—valve lesions 